\title{
MANAGEMENT OF METACARPAL FRACTURE IN A BLACK BUCK
}

\section{ANTILOPE CERVICAPRA}

\author{
Ashwani Kumar \\ Ex Veterinary Doctor, M.C. Zoological Park, Chhat Bir, Punjab, \\ Chandigarh \\ Present Address: Assistant Professor, Department of Surgery and \\ Radiology, College of Veterinary Sciences, PAU, Ludhiana, Punjab \\ 141004, India \\ Email: drashwanikumar@rediffmail.com
}

Treatment of fractures in non-domestic animals is a challenge, as regular follow ups are not possible and frequent restraining is not advisable. Also, it is difficult to restrict an animal's movement during the postoperative period. The present case report describes the management of metacarpal fracture in a Black Buck (Antilope cervicapra).

An adult male Black Buck, weighing about $25 \mathrm{~kg}$, maintained in the deer safari was presented at the zoo hospital with a complaint of non-weight bearing in the right fore limb. There was no history of an exact cause of trauma. The animal was restrained physically by holding its horns and limbs. Palpation of the right fore limb revealed crepitation indicating metacarpal fracture. No swelling or wound was observed at the site of fracture. Blood and serum samples were collected during initial examination: Haemoglobin 9.0g/dL, Total leukocyte count 7900/ $\mathrm{ml}^{3}$, Neutrophils $72 \%$, Lymphocytes $28 \%$, Serum calcium $8.8 \mathrm{~g} /$ $\mathrm{dL}$ and Phosphorus $4.3 \mathrm{~g} / \mathrm{dL}$. The limb was radiographed to know the type and location of the fracture. Dorso-palmer and lateral radiographs revealed simple but complete mid shaft fracture of right metacarpal with mildly displaced bone fragments. Reduction of the bone fragments was achieved by counter traction. Immobilization of the carpal and fetlock joints was done with cotton padding and bandages. Padded bamboo splint support was applied for retention of the apposed bone fragments. The animal was isolated and confined in a caged house separated from other Black Bucks by a chain link partition.

The animal was kept under supervision and disturbed minimally during feeding hours. The animal tolerated the bandage and bamboo splints. After 7-10 days the animal flexed its carpal joint. On close observation the metacarpal bone fragments were found straight. It was decided not to disturb the animal. After five weeks the bandaging and bamboo splints were removed and a callus was observed on palpation at the site of fracture. Carpal joint was flexed but it could only be straightened manually. The antelope was kept in the same confinement for three weeks more without any external support at the site of fracture. After this period the animal started bearing partial weight on the right fore limb. Within one week the carpal joint straightened and the animal started bearing full weight on the affected limb. Slight outward rotation of the right hoof was noticed.

(C) Zoo Outreach Organisation; www.zoosprint.org Manuscript 1408; Received 29 July 2005; Finally accepted 09 December 2005;
Surgical (Singh, G.R. et al., 1982; Singh, J. et al., 1982) and nonSurgical (Thiruthalinathan \& Swaminathan, 1996) means of fracture reduction have been described in deer. Surgical reduction of fracture management is no doubt superior but is also associated with risks of general anaesthesia; postoperative complications like infection or implant dislodgement particularly in wild animals, as they cannot be restrained frequently for antiseptic dressing of the surgical wound and parenteral medication. Secondly, such facilities are lacking in zoo hospitals. External immobilization with bamboo splints or plaster of paris, when the fracture is simple, is an alternative method to provide treatment or first aid of fracture in small wild ruminants under field conditions.

\section{REFERENCES}

Singh, G.R., I.V. Mogha and B.M. Arora (1982). Compound fracture of radius and ulna in deer (Axis axis) - A case report. Indian Journal of Veterinary Surgery 3(1): 38-41.

Singh, J., P.K. Peshin and A.P. Singh (1982). Repair of matatarsal fracture in a Barking Deer. Haryana Veterinary Journal 21(1): 48-49.

Thiruthalinathan, R. and D. Swaminathan (1996). Tibial fracture and its treatment in Sambar Deer (Cervus unicornis) - Case report. Indian Journal of Veterinary Research 5(2): 42-43.

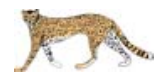

\section{Bombay Natural History Society Requires}

\section{Research Fellow:}

Should be $1^{\text {st }}$ class M.Sc. in Wildlife Bilogy or Zoology. The work involves extensive field work monitoring vulture nesting colonies and working at the conservation breeding facilities located at different parts of India. Selected candidates will be encouraged to enroll for Ph.D. programme. Computer literacy and valid driving licence for four wheeler vehicle will be considered as additional qualification. Fresh graduates will also be considered. Age - up to 30 years. Salary-Rs. 10,000/- (all inclusive) per month. Free transport facility at work will be provided.

\section{Technical Assistant:}

Should be $1^{\text {st }}$ class graduate or post graduate in Zoology. Should have at least 5 years experience in field research and have excellent communications skill. Should have good command over spoken and written English and ability to write scientific papers and reports and managing, storage of materials at the project area. Computer literacy and valid driving licence for four wheeler vehicles will be considered as additional qualification. Age - up to 30 years. Salary - All inclusive salary of Rs.12,000/- per month plus free partly furnished bachelor accommodation will be provided.

\section{Administrative Assistant:}

$\mathrm{He} /$ she should be science or Commerce Graduate. The person should be able to maintain accounts at the field projects and have working knowledge of computers. Fluency is spoken and written English is desirable. Age - up to 30 years. Salary - All inclusive salary of Rs. 7,000/- per month plus free partly furnished bachelor accommodation will be provided.

All the positions are based at Pinjore (Haryana) at present but the candidate should be prepared to work anywhere in the country. Candidates fulfilling the above requirements may please send their applications within 10 days with detailed Bio-data giving two references on the following address:

Director, Bombay Natural History Society, Hornbill House, Dr. Salim Ali Chowk, S.B. Singh Road, Mumbai 400023 Our website: www.bnhs.org 